\title{
Effect of range of spread of CD4 count and RNA level on the efficacy of HIV treatments
}

\author{
George Towfic, Samira Kettoola \\ From $16^{\text {th }}$ International Symposium on HIV and Emerging Infectious Diseases \\ Marseille, France. 24-26 March 2010
}

\begin{abstract}
Background
We used 32,297 HIV/AIDS patients' records obtained from different Midwest clinics (and published in our web portal http://hivdatamining.com) to study the effect of CD4 count and RNA level fluctuation on patients' response to HIV regimens. We had two aims: 1 . to investigate if controlling the range of spread of RNA level is more important than controlling the rate of spread of CD4 count. 2. To investigate if there is enough evidence that there exist RNA and CD4 correlation distribution that lead to better therapeutic responses.
\end{abstract}

\section{Methods}

Our HIV data analysis web portal stores patients' records obtained from different Midwest patients. We considered patients records that contains at least five laboratory tests during different patient's treatment times. Among other things, each patient laboratory test (from now on referred to a patient's record) provides CD4 count and RNA level readings.

To ensure the selection of unique datasets, we obtained ten randomly selected datasets each with 1,300 patients' records, without replacement, from the 32,297 records. To make sure that the selected records are independent, we performed a Chi Square test which yielded a $\mathrm{p}$ value of 0.0032 . We then calculated the CD4 and RNA range of spread by calculating the standard deviation (S.D.) for each patient's CD4 and RNA level. We also calculated the correlation value between the CD4 and RNA reading for each patient. At the end of this process, we obtained 3,900 datasets. In order to summarize the data, we used the resulting 3,900 datasets to construct twenty eight groups of patients' records where each group has no more than $5 \%$ difference between their average CD4, RNA, and correlation values.

\section{Results}

We calculated that the correlation value between our proposed stddiff variable (stddiff $=$ CD4 S.D. - RNA S.D.) and the correlation values of the correspond CD4, RNA values to be 0.78 with $p$ value of 0.0083 . We also found that the range of values with better (highly negative) correlation between CD4 and RNA values occurs when the calculated stddiff is not normally distributed.

\section{Discussion}

Contrary to many arguments that the change of RNA level is more significant than the change in CD4 count, we conclude that there is strong evidence, based on the above mentioned 0.78 correlation value, that both changes have significant impact on the HIV treatments' regimens. We also conclude, using the distribution of the stddiff parameter, that treatments effectiveness (represented by CD4 and RNA correlation) is strongly affected by the type of distribution of our proposed stddiff variable.

Published: 11 May 2010

doi:10.1186/1742-4690-7-S1-P15

Cite this article as: Towfic and Kettoola: Effect of range of spread of CD4 count and RNA level on the efficacy of HIV treatments.

Retrovirology 2010 7(Suppl 1):P15.

* Correspondence: george.towfic@clarke.edu

Clarke College, Dubuque, USA 